\title{
TITL: ATOMISTIC STUDIES OF GRAIN BOUNDARIES IN NiAl
}

\author{
AUTHOR(S): M. Yan \\ S. P. Chen \\ V. Vitek*
}

\section{SUBMrTtED TO: MRS Conference Proceedings}

Nov. 28-Dec. 2, 1994, Boston, MA

*Dept. of Materials Science \& Engineering

University of Pennsylvania, Philadelphia, PA

\section{MASTER}

By acceptance of this article, the publisher recognized that the $U$ S Government retains a nonexclusive, royalty-free license to publish or reproduce $\cdots$ the published form of this contribution or to allow others to do so for $U \mathbf{S}$ Government purposes.
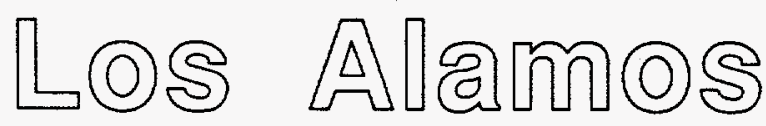

Los Alamos National Laboratory
Los Alamos, New Mexico 87545 


\section{ATOMISTIC STUDIES OF GRAIN BOUNDARIES IN NiAI}

M. Yan(1), S. P. Chen(1) and V.Vitek ${ }^{(2)}$,

(1) Theoretical Division, Los Alamos National Laboratory, Los Alamos, NM 87545

(2) Dept. of Materials Science and Engineering, Univ. of Pennsylvania, Philadelphia, PA 19104

\section{Abstract}

This paper presents the results of atomistic studies of grain boundaries in NiAl B2 alloy. The interatomic forces are described by Finnis-Sinclair type $\mathrm{N}$-body potentials, and are fitted to properties of NiAl. The results show that the structure, energy and cohesive strength of a grain boundary depend strongly on its chemical configurations, and a grain boundary with surplus of $\mathrm{Al}$ is the weakest. Energies of antisite defects at the grain boundary $\Sigma 5\{210\}$ are also calculated, and the results suggest that Al has much larger tendency to segregate at a grain boundary than $\mathrm{Ni}$ does.

\section{DISCLAIMER}

This report was prepared as an account of work sponsored by an agency of the United States Government. Neither the United States Government nor any agency thereof, nor any of their employees, makes any warranty, express or implied, or assumes any legal liability or responsibility for the accuracy, completeness, or usefulness of any information, apparatus, product, or process disclosed, or represents that its use would not infringe privately owned rights. Reference herein to any specific commercial product, process, or service by trade name, trademark, manufacturer, or otherwise does not necessarily constitute or imply its endorsement, recommendation, or favoring by the United States Government or any agency thereof. The views and opinions of authors expressed herein do not necessarily state or reflect those of the United States Government or any agency thereof. 


\section{DISCLAIMER}

Portions of this document may be illegible in electronic image products. Images are produced from the best available original document. 
ATOMISTIC STUDIES OF GRAIN BOUNDARIES IN NiAI

M. Yan(1), S. P. Chen(1) and V.Vitek(2),

(1) Theoretical Division, Los Alamos National Laboratory, Los Alamos, NM 87545

(2) Dept. of Materials Science and Engineering, Univ. of Pennsylvania, Philadelphia, PA 19104

\section{Abstract}

This paper presents the results of atomistic studies of grain boundaries in NiAl B2 alloy. The interatomic forces are described by Finnis-Sinclair type $\mathrm{N}$-body potentials, and are fitted to properties of NiAl. The results show that the structure, energy and cohesive strength of a grain boundary depend strongly on its chemical configurations, and a grain boundary with surplus of $\mathrm{Al}$ is the weakest. Energies of antisite defects at the grain boundary $\Sigma 5\{210\}$ are also calculated, and the results suggest that $\mathrm{Al}$ has much larger tendency to segregate at a grain boundary than $\mathrm{Ni}$ does.

\section{Introduction}

$\mathrm{NiAl} \mathrm{B2}$ ordered compound is a potential material for high temperature structural applications because of its high melting temperature, excellent oxidation resistance, good thermal conductivity, etc $[1,2]$. However, this material is brittle at room temperature, and in polycrystals fracture is predominantly along grain boundaries. Such interfacial brittleness seems to be an intrinsic property of this material, because analysis of grain boundary chemistry by Auger spectroscopy indicates no detectable impurity segregations [3]. Understanding of interfacial mechanical properties requires the knowledge of grain boundary structure, chemistry, and chemical ordering at the microscopic level. However, unlike $\mathrm{Ni}_{3} \mathrm{Al}$, in which extensive studies have been performed in the past years, the study of grain boundaries in NiAl is still very limited. The purpose of this work, therefore, is to study grain boundaries in $\mathrm{NiAl}$ by atomistic simulations. The interatomic potentials were fitted specifically to properties of $\mathrm{NiAl}$. We expect that the results obtained from this study will shed some light on the understanding of interfacial mechanical properties of $\mathrm{NiAl}$.

\section{Interatomic Potentials}

The empirical N-body central force potentials were constructed in the framework of the Finnis-Sinclair scheme [4]. The total energy of the alloy system of $\mathrm{N}$ atoms is written as:

$$
E_{t o t}=\frac{1}{2} \sum_{i=1}^{N}\left[\sum_{j \neq i} V_{S_{i} S_{j}}\left(R_{i j}\right)-\sqrt{\sum_{j \neq i} \Phi_{S_{i} S_{j}}\left(R_{i j}\right)}\right]
$$


where the first term results from direct interaction between two atoms and the second term is the $\mathrm{N}$ body attractive part of the cohesive energy [5]. Both $V$ and $\Phi$ are empirically fitted pair potentials depending on the species $S_{i}$ and $S_{j}$, and $R_{i j}$ is the separation of atoms $i$ and $j$. The Ni-Ni potential was fitted to the experimentally known lattice parameter, cohesive energy, elastic constants and vacancy formation energy of pure $\mathrm{Ni}$ [6]. In the current study it is adjusted at separations smaller than the first nearest neighbor distance in pure $\mathrm{Ni}$ to reproduce the pressure-volume relation calculated from the universal equation [7]. The fitting of Al-Al potential was similar to that for $\mathrm{Ni}$ $\mathrm{Ni}$ [8], while in the current study the $\mathrm{Al}-\mathrm{Al}$ repulsive interaction at separations smaller than the first nearest neighbor distance in pure $\mathrm{Al}$ was increased, in order to make the $\mathrm{Al}$ antisite defect on $\mathrm{Ni}$ site energetically unfavorable relative to the formation of double vacancies on $\mathrm{Ni}$ sites. This is based on the evidence that $\mathrm{Al}$ enrichment in $\mathrm{NiAl}$ is associated with the formation of constitutional vacancies on $\mathrm{Ni}$ sites [9].

The $\Phi_{\mathrm{NiAl}}$ potential was taken as the geometric mean of the $\Phi$ potentials for pure Ni and pure $\mathrm{Al}$, which is consistent with its interpretation in terms of hopping integrals [5]. The $\mathrm{V}_{\mathrm{NiAl}}$ potential was fitted to reproduce experimentally known lattice constant, cohesive energy and elastic constants of NiAl B2 compound. At atomic separations smaller than the first nearest neighbor distance the $\mathrm{V}_{\mathrm{NiAl}}$ potential was adjusted to comply with the pressure-volume relation calculated from the universal equation [7].

With these potentials the antisite defect energy of putting $\mathrm{Ni}$ on $\mathrm{Al}$ site is $-0.64 \mathrm{eV}$, and that of putting $\mathrm{Al}$ on $\mathrm{Ni}$ site is $2.53 \mathrm{eV}$. Exchange of a $\mathrm{Ni}$ atom and an $\mathrm{Al}$ atom thus results in energy increase by $1.89 \mathrm{eV}$. This has been found to stabilize the B2 structure up to $2000 \mathrm{~K}$ [10]. Creating one $\mathrm{Ni}$ vacancy increases the energy by $1.3 \mathrm{eV}$. However, if considering the free energy, then putting one $\mathrm{Al}$ on $\mathrm{Ni}$ site is less favored than creating two $\mathrm{Ni}$ vacancies, and this agrees with experiments [9]. In addition, these potentials ensure the NiAl B2 structure energetically favored over the $\mathrm{L} 1_{0}$ structure, and reproduce the energy of the $\{110\}$ antiphase boundary as $437 \mathrm{~mJ} / \mathrm{m}^{2}$, which is within the experimentally measured range [2]. Furthermore, with the current potentials the properties of $\mathrm{Ni}_{3} \mathrm{Al} \mathrm{Ll}_{2}$ compound can also be reproduced very well, although they were not directly included in the potential fitting [10]. This enables the application of these potentials over a wide range of compositions of $\mathrm{Ni}-\mathrm{Al}$ alloy, and to a wide range of atomic neighbor environments, as are often encountered in calculations of defects. Details of the potential fitting will be published elsewhere [10].

\section{Results}

\section{Strength, energy and cohesive strength of grain boundaries}

The first step of the study was to investigate the structure, energy and cohesive strength of grain boundaries by static calculations, and the detailed procedure has been described previously 
[11]. For each boundary studied, many initial configurations which differ in the rigid shifts between the two grains were employed, in order to find the global minimum energy structure among several metastable structures.

In B2 lattice there are two kinds of symmetric grain boundaries, depending on the orientation of the boundary plane $\{\mathrm{hkl}\}$. In the first kind, each $\{\mathrm{hkl}\}$ plane consists of $50 \% \mathrm{Ni}$ and $50 \% \mathrm{Al}$, such as the $\{110\}$ plane, so a grain boundary can be uniquely defined. (It is denoted as $\mathrm{mix} / \mathrm{mix}$ boundary in the later text, where " $/$ " represents the position of the boundary). In the second kind, each (hkl $\}$ plane consists of either $100 \% \mathrm{Ni}$ or $100 \% \mathrm{Al}$, such as the $\{100\}$ plane. Therefore when a grain boundary is formed it can have three configurations, $\mathrm{Ni} / \mathrm{Al}, \mathrm{Ni} / \mathrm{Ni}$ and $\mathrm{Al} / \mathrm{Al}$, and the occurrence of each configuration is with equal opportunity.

Figs.1(a)-(c) show the relaxed structures of $\Sigma 5\{210\}[001]$ boundary with $\mathrm{Ni} / \mathrm{Al}, \mathrm{Ni} / \mathrm{Ni}$ and $\mathrm{A} / \mathrm{Al}$ configurations, respectively, and each corresponds to the minimum energy structure among several metastable structures. The light and dark shaded circles represent $\mathrm{Al}$ and $\mathrm{Ni}$ atoms, respectively, and different symbols represent different atomic positions along the [001] direction, which is perpendicular to the paper. The solid square represents the structural unit in each structure, and the horizontal solid line represents the grain boundary plane. It can be seen that these three structures show different features. With the $\mathrm{Ni} / \mathrm{Al}$ configuration, the boundary plane ends up with pure $\mathrm{Al}$ after relaxations, and adjacent to this plane are $\mathrm{Ni}$ atoms distributed asymmetrically on both sides, due to the rigid shift between the two grains along the [001] direction. For the $\mathrm{Ni} / \mathrm{Ni}$ and $\mathrm{Al} / \mathrm{Al}$ configurations, however, two layers coalesce after relaxations and the boundary plane ends up with 50\% Ni and 50\%Al. Adjacent to the boundary plane are either $\mathrm{Ni}$ atoms (for $\mathrm{Ni} / \mathrm{Ni}$ configuration) or $\mathrm{Al}$ atoms (for $\mathrm{Al} / \mathrm{Al}$ configuration) distributed symmetrically on both sides.

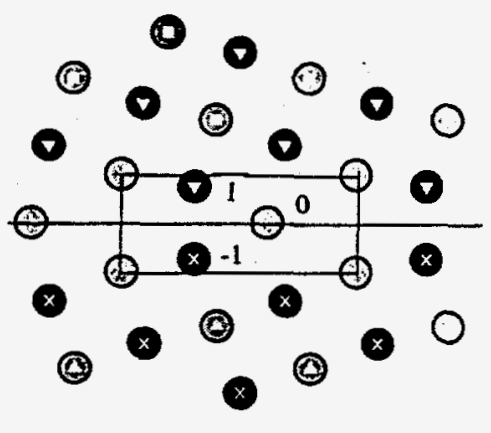

(a)

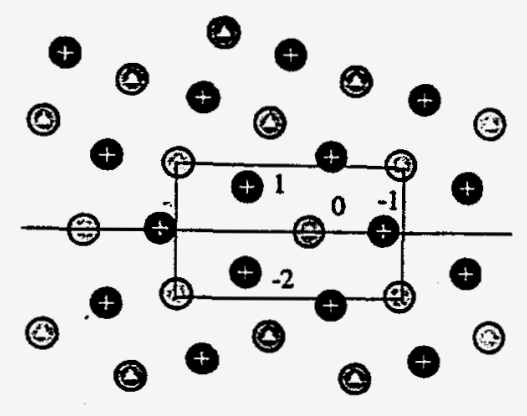

(b)

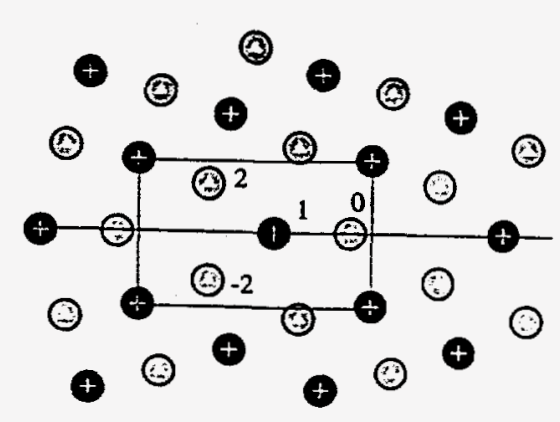

(c)

Fig.1. Relaxed structures of the $\Sigma 5\{210\}[001]$ grain boundary with different chemical configurations; (a) Ni/Al, (b) Ni/Ni and (c) Al/Al.

The grain boundary energy, $\gamma$, and grain boundary expansion, $\Delta Y$, also depend on grain boundary chemical configurations, and these are shown in Figs.2(a)(b). For the symmetrical tilt 
boundaries which can have three different chemical configurations, such as the $\Sigma 5\{210\}[001]$, $\Sigma 29\{520\}[001]$ and $\Sigma 11\{113\}[110]$ boundaries, it can be seen that $\gamma(\mathrm{Al} / \mathrm{Al})>\gamma(\mathrm{Ni} / \mathrm{Al})>\gamma(\mathrm{Ni} / \mathrm{Ni})$, and $\Delta \mathrm{Y}(\mathrm{Al} / \mathrm{Al})>\Delta \mathrm{Y}(\mathrm{Ni} / \mathrm{Al})>\Delta \mathrm{Y}(\mathrm{Ni} / \mathrm{Ni})$. This feature is similar to that found for $\mathrm{Ni}_{3} \mathrm{Al}$ grain boundaries [12], as well as to previous calculated results of $\mathrm{NiAl}$ grain boundaries by using potentials fitted to $\mathrm{Ni}_{3} \mathrm{Al}$ alloy [13]. In addition, for those boundaries with mix/mix configuration, such as the symmetric tilt boundaries $\Sigma 5\{310\}[001], \Sigma 13\{510\}[001]$ and $\Sigma 9\{114\}[110]$, the values of $\gamma$ and $\Delta \mathrm{Y}$ are always smaller than those of the boundaries with $\mathrm{Al} / \mathrm{Al}$ configuration.

The Griffith cohesive strength, which is the ideal work needed to break a crystal along a grain boundary or along a plane in the bulk, is also calculated for grain boundaries and several planes with low indices. The results show that $\{110\}$ is the weakest plane comparing with other planes in the bulk. From experimental observations it is indeed the most common cleavage plane [14]. The calculated cohesive strength of grain boundaries, G, is shown in Fig.2(c), in which the straight line represents the cohesive strength of the $\{110\}$ plane. It can be seen that for boundaries which can have different chemical configurations, the values of $G$ follow the relation $\mathrm{G}(\mathrm{Ni} / \mathrm{Ni})>\mathrm{G}(\mathrm{Ni} / \mathrm{Al})>\mathrm{G}(\mathrm{Al} / \mathrm{Al})$, which indicate that a boundary with $\mathrm{Ni} / \mathrm{Ni}$ configuration is the strongest, and that with the $\mathrm{Al} / \mathrm{Al}$ configuration is the weakest. Furthermore, the cohesive strength of boundaries with mix/mix configuration is larger than those of the $\mathrm{Al} / \mathrm{Al}$ and $\mathrm{Ni} / \mathrm{Al}$ boundaries, and sometime even larger than that of $\mathrm{Ni} / \mathrm{Ni}$ boundaries.
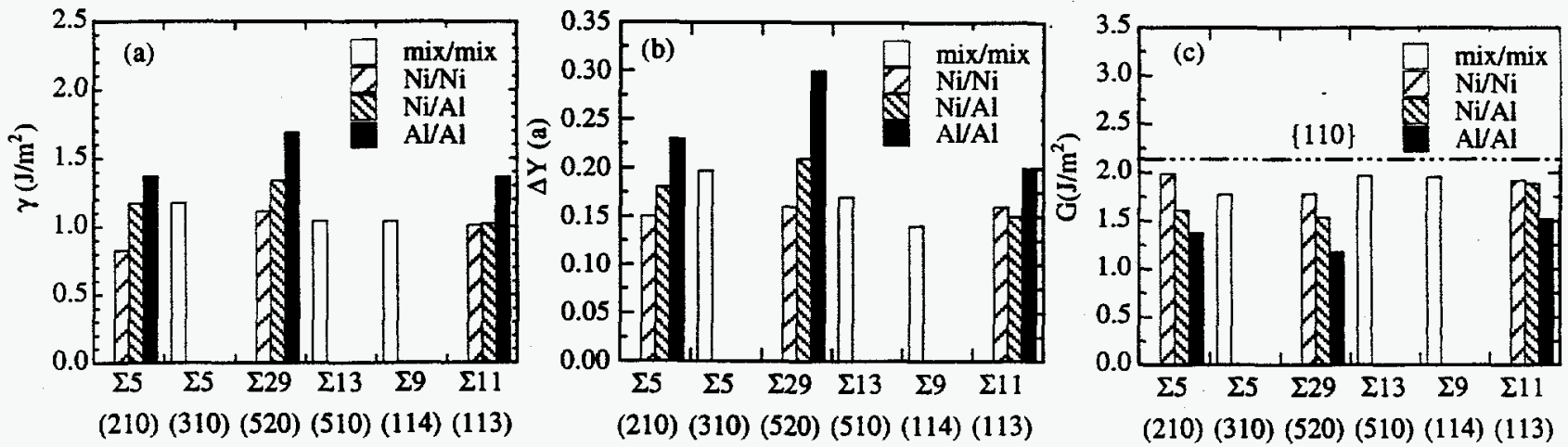

Fig.2. Calculated values of (a) grain boundary energy, $\gamma$, (b) grain boundary expansion in the direction perpendicular to the boundary plane, $\Delta Y$, and (c) Griffith cohesive strength, $G$.

The calculated cohesive strength of grain boundaries is smaller than that in the bulk. This is consistent with experimental observations that in $\mathrm{NiAl}$ polycrystals the predominant fracture mode is intergranular. The results also suggest that grain boundaries possessing more Al will fracture much more easily than grain boundaries with stoichiometric composition or those possessing more $\mathrm{Ni}$. In addition to their lower cohesive strength, the relatively larger volume expansion associated with boundaries possessing more $\mathrm{Al}$ can also be expected to make the crack initiation much easier. 
The antisite defect energies at the $\Sigma 5\{210\}$ grain boundary have been calculated by creating one antisite defect each time at a site close to the boundary and then relax the whole block to the minimum energy. The calculated results are shown in Figs.3(a)(b), in which $\Delta \mathrm{E}(\mathrm{Ni}->\mathrm{Al})$ and $\Delta \mathrm{E}(\mathrm{Al}->\mathrm{Ni})$ represent the antisite defect energies by putting $\mathrm{Ni}$ on $\mathrm{Al}$ site, and putting $\mathrm{Al}$ on $\mathrm{Ni}$ site, respectively. The horizontal solid line in each figure represents the corresponding antisite defect energy in the bulk. The layer indices are consistent with those shown in Fig.1(a)-(c).
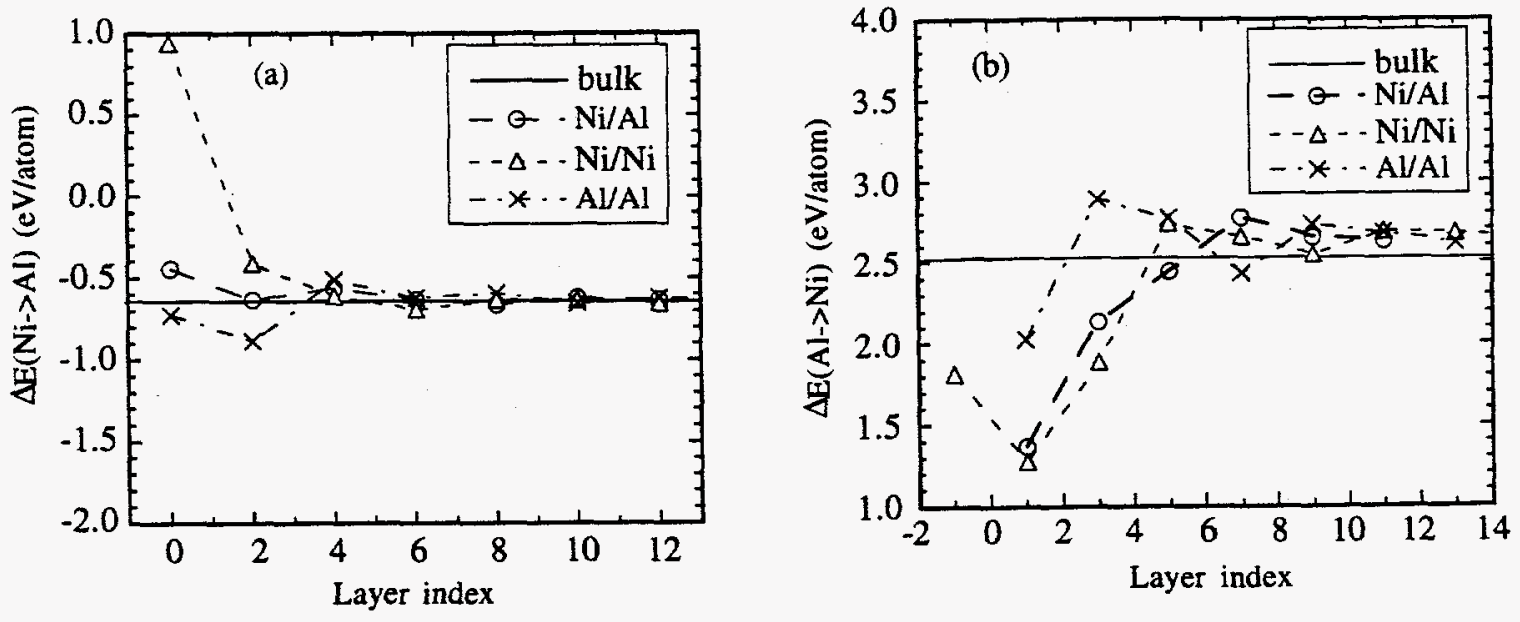

Fig.3. Calculated values of antisite defect energies; (a) putting $\mathrm{Ni}$ on $\mathrm{Al}$ sites, $\triangle \mathrm{E}(\mathrm{Ni}->\mathrm{Al})$, and (b) putting $\mathrm{Al}$ on $\mathrm{Ni}$ sites, $\Delta \mathrm{E}(\mathrm{Al}->\mathrm{Ni})$.

Fig.3(a) shows that for all three chemical configurations, values of $\Delta \mathrm{E}(\mathrm{Ni}->\mathrm{Al})$ at the layer $\# 0$ are either larger or a little smaller than that in the bulk. At the layer \#2, the value of $\triangle \mathrm{E}(\mathrm{Ni}->\mathrm{Al})$ is smaller by $0.24 \mathrm{eV}$ than that in the bulk at the $\mathrm{Al} / \mathrm{Al}$ boundary, but larger than that in the bulk at the $\mathrm{Ni} / \mathrm{Al}$ and $\mathrm{Ni} / \mathrm{Ni}$ boundaries. Such results suggest that if $\mathrm{Ni}$ is in surplus in the bulk, Ni will segregate at the layer \#2 at the Al/Al boundary. This is similar as the observation at the $\Sigma 5\{310\}[001]$ boundary from HREM and calculations [15]. The driving force is to releases the strain caused by strong repulsion between two $\mathrm{Al}$ atoms across the boundary, as shown in Fig.1(c). However, Ni will have no or very weak driving force to segregate to Al sites located right at the boundary plane, denoted as the layer $\# 0$ at all three boundaries. This could be related with the fact that the grain boundaries are associated with larger free volumes due to expansions (Fig.1(b)), so they do not favor Ni atoms at the boundary plane because the size of Ni is smaller that that of $\mathrm{Al}$.

The situation for putting $\mathrm{Al}$ on $\mathrm{Ni}$ sites at a grain boundary, however, is quite different. Fig.3(b) shows that, for the $\mathrm{Ni} / \mathrm{Ni}$ and $\mathrm{A} 1 / \mathrm{Al}$ boundaries in which there are $\mathrm{Ni}$ sites at the boundary plane (layer \#-1 and layer \#1, respectively), placing $\mathrm{Al}$ on these $\mathrm{Ni}$ sites is favored over placing $\mathrm{Al}$ on Ni site in the bulk. This is true even at layers adjacent to the boundary plane, such as the layer 
$\# 1$ in the $\mathrm{Ni} / \mathrm{Al}$ and $\mathrm{Ni} / \mathrm{Ni}$ boundaries. Such results suggest that if there is extra $\mathrm{Al}$ in the bulk, the $\mathrm{Al}$ will prefer to segregate to grain boundaries because the energy increase is only from $1.3 \mathrm{eV}$ to $2.0 \mathrm{eV}$. But if leaving the extra $\mathrm{Al}$ on $\mathrm{Ni}$ site in the bulk or creating two $\mathrm{Ni}$ vacancies the energy increase will be $2.53 \mathrm{eV}$ or $2.6 \mathrm{eV}$, respectively.

\section{Conclusions}

In $\mathrm{NiAl}$ the structure, energy and cohesive strength of grain boundaries depend strongly on their chemical compositions. The boundaries which possess more $\mathrm{Al}$ are the weakest. Ni has little tendency to segregate at a grain boundary plane, but can segregate at layers adjacent to a boundary plane; $\mathrm{Al}$, on the other hand, prefers to segregate at both the boundary plane and in the vicinity of the boundary plane. The driving force for $\mathrm{Al}$ segregation is much larger than that for $\mathrm{Ni}$.

\section{Acknowledgment}

The authors would like to acknowledge the financial support from the Department of Energy, Office of Basic Energy Science, under Grant. No. DE-FG02-87ER45295 (MY and VV) and at Los Alamos National Laboratory.

\section{References}

1. R. Darolia, JOM 43, 44 (1991).

2. D. Miracle, Acta Metall. 41, 649-684 (1993).

3. E. P. George and C. T. Liu, J. Mater. Res. 5, (1990).

4. M. W. Finnis, and J. E. Sinclair, Phil. Mag. A 50, 45 (1984).

5. G. J. Ackland, M. W. Finnis, and V. Vitek, J. of Phys. F, 18, L153 (1988).

6. G. J. Ackland, G. Tichy, V. Vitek, and M. W. Finnis, Phil. Mag. A 56, 735 (1987).

7. J. H. Rose, J. R. Smith, F. Guinea and J. Ferrante, Phys. Rev. B. 29, 2963 (1984).

8. V. Vitek, G. J. Ackland, and J. Cserti, in Alloy Phase Stability and Design (eds. G.M. Stocks, D. P. Pope, and A.F. Giamei ), Mater. Res. Soc. Symp., 186, 237 (1991).

9. A. J. Bradley and A. Taylor, Proc. Roy. Soc. A 159, 56 (1937).

10. M. Yan, V. Vitek, and S. P. Chen, in preparation.

11. A. P. Sutton and V. Vitek, Phil. Trans. Royal Soc., London A 309, 1, (1983).

12. S. P. Chen, A. F. Voter, A. M. Boring, R. C. Albers, and P. J. Hay, in High Temperature Ordered Intermetallic Alloys III, (eds. C. T. Liu, A. I. Taub, N. S. Stoloff and C. C. Koch), Mater. Res. Soc. Symp. Proc. 133, 149 (1989).

13. G. Petton and D. Farkas, Scrip. Metall., 25, 55 (1991)

14. R. Darolia, K. M. Chang, and J. E. Hack, Intermetallics 1, 65 (1993).

15. R. W. Fonda, M. Yan, and D. E. Luzzi, submitted to Phil. Mag. Lett. (1994). 